\title{
DERLEME
}

\section{Bakla (Fabasea) mı Suçlu Genleriniz mi?}

\author{
Cahit ERKUL ${ }^{1}$, Aliye ÖZENOĞLU ${ }^{2}$
}

\section{$\ddot{\mathbf{O Z Z}}$}

Glikoz-6-fosfat dehidrogenaz (G6PD) eksikliği, dünya çapında en az 400 milyon kişiyi etkileyen, dünyadaki en yaygın enzim eksikliğidir. Bu metabolik enzim, eritrositlerin oksidatif strese karşı korunmasında önemli bir rol oynar, böylece hemoliz önlenir. Tarihsel olarak, baklanın (fabasea) tüketilmeye başlanmasından sonra patolojik bir bozukluk fark edilmiş, daha sonra bu durum G6PD eksikliği olarak tanımlanmıştır. Eksik G6PD alelleri dünya çapında görülmektedir. Fabasea meyvesinin içerdiği besin öğeleri incelendiğinde, proteinler, karbonhidratlar, suda çözünen vitaminler (folik asit, niasin ve $\mathrm{C}$ vitamini), diyet lifi açısından zengin olduğunu ortaya konulmuştur. Favizm, bakla tüketiminden kaynaklanan hemolitik anemiyi tanımlamak için kullanılan bir terimdir. G6PD eksikliği ile ilişkisi bilimsel ve tıbbi literatürde yer almıştır. Nutrigenetik, hastalık etiyolojisinde rol oynayabilecek beslenme ve genetik faktörlerin etkileşimi ile ilgilidir. Bu derlemenin amacı G6PD eksikliğinin patofizyolojisi, genetik özellikleri ve favizm ile ilişkisini ortaya koymak ve genetik yapıya göre beslenmenin (nutrigenetik) önemine vurgu yapmaktır.

Anahtar Kelimeler: Fabasea; Favizm; Nutrigenetik

\section{Which is Guilty? Fabaceae or Your Genes \\ Cahit ERKUL ${ }^{1}$, Aliye ÖZENO $\breve{G} L U^{2}$}

\begin{abstract}
Glucose-6-phosphate dehydrogenase (G6PD) deficiency is the most common enzyme deficiency in the world, affecting at least 400 million people worldwide. This metabolic enzyme plays an important role in protecting erythrocytes against oxidative stress, thus preventing hemolysis. Historically, a pathological disorder was noticed after the consumption of fabaceae, which was later defined as G6PD deficiency. Missing G6PD alleles occur worldwide. When the nutritional elements of the fabaceae fruit were examined, it was revealed that it is rich in proteins, carbohydrates, water-soluble vitamins (folic acid, niacin and vitamin C), dietary fiber. Favism is a term used to describe hemolytic anemia caused by consumption of fabaceae. Its association with G6PD deficiency has been reported in the scientific and medical literature. Nutrigenetics is concerned with the interaction of nutrition and genetic factors that may play a role in disease etiology. The aim of this review is to reveal the pathophysiology of G6PD deficiency, its genetic characteristics and its relationship with favism, and to emphasize the importance of nutrition (nutrigenetics) according to genetic structure.
\end{abstract}

Keywords: Fabaceae; Favism; Nutrigenetics

${ }^{1}$ Yakın Doğu Üniversitesi, Sağlık Bilimleri Enstitüsü, KKTC.

${ }^{2}$ Üsküdar Üniversitesi, Sağlık Bilimleri Fakültesi, İstanbul Türkiye Sorumlu Yazar: Cahit ERKUL

E-posta adresi: dyt.cahit@gmail.com ORCID No: 0000-0003-0940-1129

Gönderi Tarihi: 20.08 .2021

Kabul Tarihi: 10.12 .2021 


\section{GíRiș}

Büyük bir matematikçi olan Sisamlı Pisagor, M.Ö.5. yüzyılda baklanın insanlar için tehlikeli ve hatta ölümcül olabileceğini ilk kez kesin olarak belirtmiştir. $\mathrm{Bu}$ buluşu kendisine beslenme biliminde bir yer verirken nutrigenomikte vermemektedir; çünkü görünüşe göre tehlikenin bakla yiyen kişinin genotipine bağlı olduğunun farkında değildir. Genlerin rolü ancak glukoz-6fosfat dehidrogenaz (G6PD) eksikliğinin keşfedildiği 1956'da netleşmiştir. Bu kalıtsal özelliğin, o zamana kadar ilgisiz görünen en az üç hastalığın altında yattığı hızla ortaya çıkmıştır: ilaç kaynaklı hemolitik anemi, şiddetli neonatal sarılık ve favizm. G6PD eksikliğinin tüm yönleriyle ilgili incelemeleri içeren geniş bir literatüre sahip olduğu görülmektedir (1).

Glikoz-6-fosfat dehidrogenaz (G6PD) eksikliği, dünya çapında en az 400 milyon kişiyi etkileyen, dünyadaki en yaygın enzim eksikliği olarak bilinmektedir. G6PD eksikliği, G6PD genindeki mutasyonlardan kaynaklanan $\mathrm{X}$ kromozomuna bağlı kalıtsal bir genetik kusurdur. Genetik eksiklik kadınlar tarafından taşınmaktadır, ancak esas olarak erkekleri etkilemektedir (G6PD eksikliği olan kişilerin \%90'1 erkektir). Büyük ölçüde Afrika,
Akdeniz Havzası, Hindistan, Güneydoğu Asya veya Latin Amerika kökenli nüfusları etkilemektedir (2).

$\mathrm{Bu}$ metabolik enzim, eritrositlerin oksidatif strese karşı korunmasında önemli bir rol oynamaktadır, böylece hemoliz önlenmektedir. G6PD eksikliği olan kişiler, ilaçlar (örneğin, bazı antimalaryal ilaçlar veya antibiyotikler) veya kimyasallar (örneğin naftalin) gibi oksidanlara duyarlıdır. En yaygın klinik belirtiler yenidoğan sarılığı ile akut hemolitik anemidir ve çoğu hastada eksojen bir ajan tarafindan tetiklenmektedir(3).

Bugüne kadar, G6PD'nin 400'den fazla farklı biyokimyasal varyantı, çeşitli biyokimyasal özellikleri temelinde ve G6PD geninde toplam 217 farklı nokta mutasyonu tanımlanmıştır. $\mathrm{Bu}$ biyokimyasal varyantların çoğu oksidatif tetikleyicilere maruz kalana kadar asemptomatiktir. Bu tetikleyicilere maruz kalma, en yaygın olarak 2 klinik sonuçtan 1'inde ortaya çıkmaktadır. Eksikliklerin çoğuna karşılık gelen ilk durumda, mutasyon, enzim işlevinde yalnızca semptomlara yol açmak için yeterli olmayan hafif bir bozulmaya neden olmaktadır. Bu nedenle, etkilenen bireyler genellikle durumlarının farkında değildir. Daha az 
yaygin durumda, mutasyon G6PD enziminin aktivitesini büyük ölçüde azaltmaktadır. Bu durum, hemolitik anemi ve yenidoğanlarda artan bilirubin seviyeleri nedeniyle yenidoğan sarılığı gibi ciddi klinik belirtilere yol açabilmektedir. Kronik hemolitik anemi ve sık görülen akut hemolitik anemi, her yaşta ortaya çıkabilen potansiyel olarak ölümcül akut böbrek yetmezliği ile ilişkilendirilebilir (4).

Tarihsel olarak, baklanın tüketilmeye başlanmasından sonra patolojik bir bozukluk fark edilmiş, daha sonra bu durum G6PD eksikliği olarak tanımlanmıştır. Yirminci yüzyılın başlarında Güney İtalya ve Sardinya'daki birkaç doktor, o dönemde favizm denen şeyi klinik olarak tanımlanmıştır. Bununla birlikte, bakla tüketimine verilen yanıtın tutarsız olduğu belirtildiğinden, favizmin patogenezine ilişkin yaygın teoriler alerji veya toksik etkilerle ilişkilendirilmiştir. Daha sonra 1956'da, antimalaryal ilaç primakinin tarafından tetiklenen hemolitik anemi geliştiren hastaların kırmızı kan hücrelerinde çok düşük miktarda G6PD aktivitesi gösterdiği bulunmuştur. Sardinya'da bakla tüketilmesinden sonra veya bazen bitkinin poleninin solunmasından sonra ortaya çıkan şiddetli hemolitik anemili hastalarda benzer bir eğilim kaydedilmiştir (5).

$\mathrm{Bu}$ derlemenin amacı G6PD eksikliğinin patofizyolojisi, genetik özellikleri ve favizm ile ilişkisini ortaya koymak ve genetik yapıya göre beslenmenin (nutrigenetik) önemine vurgu yapmaktır.

\section{Patofizyoloji}

G6PD eksikliği ilk olarak 1950'lerde, sitma önleyici ilaçlara maruz kaldıklarında hemolitik anemi geliştiren az sayıda Amerikan askerinde tanımlanmıştır. Daha sonraki yıllarda hastalığın genetik nedeni tespit edilmiş ve $\mathrm{X}$ kromozomu üzerinde yer alan G6pdx genindeki mutasyonlara bağlanmıştır. Gen, X kromozomu üzerinde yer aldığı için cinsiyete bağlı olarak kalıtılmaktadır. Erkeklerde X kromozomunun yalnızca bir kopyası vardır; bu nedenle, mutasyonu miras alanlar hemizigot olarak kabul edilmektedir. Bununla birlikte, dişiler homozigot (iki çift mutant alleller) veya heterozigot (sadece bir mutant allel) olabilmektedir. Homozigot dişilerde G6PD eksikliği olurken, heterozigot dişiler taşıyıcı olmaktadır. Taşıyıcılar genellikle durumdan 
etkilenmemekte ve nadiren semptomlar ortaya çıkmaktadır. G6PD eksikliği olan nüfusun çoğunluğunda, özellikle erkeklerde, belirli oksidatif stres faktörlerine (örneğin bakla), oksidatif ilaçlara (örneğin sitma önleyici maddeler) ve enfeksiyonlara maruz kalmadıkları takdirde herhangi bir semptom gözlemlenmemiştir (6).

G6PD, pentoz fosfat yolağındaki ilk reaksiyonu katalize ederek, indirgenmiş nikotinamid adenin dinükleotid fosfat (NADPH) formundaki tüm hücrelere indirgeme yeteneği üreten bir enzimdir. NADPH, hücrelerin birkaç oksitleyici maddenin neden olduğu oksidatif strese karşı dengelenmesine izin vermekte ve indirgenmiş glutatyon formunu korumaktadır. İndirgenmiş glutatyon formu, hidrojen peroksit ve diğer oksijen radikallerinin indirgenmesi için ve hemoglobini indirgenmiş durumda tutmak için çok önemlidir. Kırmızı kan hücrelerinde mitokondri olmadığından, tek NADPH kaynağı pentoz fosfat yoludur. Sonuç olarak, bir kırmızı kan hücresindeki oksidatif hasara karşı savunma tamamen G6PD'ye bağlıdır (7).

G6PD eksikliği, erkeklerde kadınlara göre daha fazla görülen favizm ile tanımlanan tipik bir X- bağlantılı kalıtım modeli sergilemektedir. Erkekler G6PD geni için hemizigottur. Öte yandan dişiler, her X kromozomunda G6PD geninin iki kopyasına sahiptir. Bu nedenle, heterozigot olabilmekte veya normal gen ekspresyonuna sahip olabilmektedirler. G6PD eksikliği olan heterozigot dişiler, $\mathrm{X}$ kromozomu inaktivasyonunun bir etkisi olarak genetik mozaiklerdir; yani heterozigot bir dişinin anormal hücreleri, G6PD'den yoksun bir erkeğe benzer şekilde G6PD için eksik olabilmektedir. Sonuç olarak, bu tür dişiler, eşdeğer patofizyolojik fenotipe karşı savunmasız olabilmektedirler. Heterozigot dişiler tipik olarak G6PD eksikliği olan erkeklerden daha az şiddetli klinik tablolara sahipken, bazılarında şiddetli akut hemolitik anemi gelişebilmektedir (8).

\section{Sinıflandırma}

G6PD enziminin biyokimyasal varyantları, kırmızı kan hücrelerindeki enzimatik aktivite ve klinik belirtiler temelinde 5 sinıfa ayrılmaktadır. 
Sınıf I varyantları, kronik nonferositik hemolitik anemiye yol açan ciddi bir enzimatik aktivite eksikliği ile ilişkilidir. $\mathrm{Bu}$ varyantlar dünyanın herhangi bir yerinde çok düşük bir frekansta düzensiz olarak ortaya çıkmaktadır. Kronik nonferositik hemolitik anemili hastalar, normal G6PD enzim aktivitesinin \%10'undan daha azına sahiptir. Sınıf I varyantları olan bazı hastalarda, rezidüel enzim aktivitesi seviyeleri o kadar düşüktür ki, yeterli bir NADPH konsantrasyonu sürdürülemez ve tekrarlayan akut hemoliz epizodları ile kronik hemolitik anemiye yol açmaktadır. Bu hastalar sıklıkla yenidoğan sarılığı öyküsüne ve klinik olarak en şiddetli belirtilere sahiptir (9).

Sinıf II varyantları olan hastalar normal G6PD aktivitesinin \%10'undan daha azına sahiptir, ancak kronik nonferositik hemolitik anemi yoktur. Sinıf II varyantları arasında ortak Akdeniz (G6PD Akdeniz) ve yaygın şiddetli Asya varyantları (örneğin, G6PD Kanton) bulunmaktadır. $\mathrm{Bu}$ varyantlara sahip hastalar, tipik olarak enfeksiyon, oksidatif ilaçlara maruz kalma veya sadece bakla tüketiminin neden olduğu aralıklı akut hemolizden muzdariptir.
Sinıf III varyantlarında enzim orta derecede eksiktir (hastalarda \%10-60 rezidüel enzim aktivitesi vardır) ve ortak Afrika (G6PD A) formunu ve Güneydoğu Asya'daki Mahidol varyantlarını içermektedir. Sınıf III varyantları olan hastalarda, genellikle enfeksiyon, oksidatif ilaçlar, yiyecekler tarafindan tetiklenen aralıklı hemoliz vardır.

Sınıf IV varyantlarında çok hafif enzim eksikliği veya hiç enzim eksikliği görülmemektedir (hastalar normal enzim aktivitesinin $>\% 60$ 'ına sahiptir) ve hemoliz ile ilişkili değildir.

Sınıf V varyantları, normalden daha yüksek enzim aktivitesi ile ilişkilidir (10).

\section{Epidemiyoloji}

Eksik G6PD alelleri dünya çapında görülmektedir. En az 400 milyon insanın G6PD geninde eksikliğe neden olan bir mutasyon taşıdığ tahmin edilmektedir. En yüksek yaygınlık Afrika, Güney Avrupa, Orta Doğu, Güneydoğu Asya ile Orta ve Güney Pasifik Adaları'nda bildirilmiştir. Ancak, yeni göçler nedeniyle, eksik aleller günümüzde Kuzey-Güney Amerika'da ve Kuzey Avrupa'nın bazı kısımlarında da oldukça yaygındır. 
Herhangi bir popülasyon için enzim aktivitesi taramasına dayalı epidemiyolojik çalışmalar kesin olmadığından ve küresel kapsamı genişletmediğinden, her alelin G6PD eksikliğinin genel prevalansına nicel katkısının tanımı hala zordur. Son yıllarda, G6PD eksikliğinin yaygınlığını haritalamak için moleküler analiz kullanılmıştır (11).

G6PD eksikliğinin yüksek prevalansının olduğu çoğu alanda, birkaç polimorfik alel bulunur. Afrika'nın tropikal bölgeleri, G6PD A- varyantının G6PD eksikliğinin yaklaşık \%90'ını oluşturduğu bir istisnadır. G6PD A- Kuzey ve Güney Amerika'da, Batı Hint Adaları'nda ve Afrika kökenli insanların bulunduğu bölgelerde de sık görülür. Dahası, G6PD A- İtalya, Kanarya Adaları, İspanya ve Portekiz ile İran, Misır ve Lübnan da dahil olmak üzere orta doğuda oldukça yaygındır (12).

\section{Genetik}

G6PD geninin (Xq28 ile eşleşen) 13 ekzonu vardır ve dimer ve tetrameri, G6PD'nin enzimatik olarak aktif formları olan (monomerin enzim aktivitesi yoktur) 514 amino asitlik (aa) bir polipeptit zincirini kodlamaktadır. X bağlantısının sonuçları çok önemlidir.

Birincisi, bir erkek sadece bir G6PD aleline sahip olduğundan, o sadece hemizigot G6PD normal veya hemizigot G6PD eksik olabilir; bunun yerine iki G6PD aleline sahip bir dişi, homozigot G6PD normal veya homozigot G6PD eksikliği veya G6PD eksikliği için heterozigot olabilir.

İkincisi, popülasyon genetiği yasalarına uygun olarak, herhangi bir popülasyonda heterozigotlar hemizigot G6PD eksikliği olan erkeklerden daha s1k görülürken, homozigot G6PD eksikliği olan dişiler çok daha nadirdir.

Üçüncüsü, çoğu X bağlantılı gen gibi G6PD'de de $\mathrm{X}$ kromozomu inaktivasyonu fenomenine maruz kaldığından, heterozigot dişiler genetik mozaiklerdir; kanlarında G6PD normal ve G6PD eksik kırmızı hücrelerin bir karışımı vardır.

İki tür arasındaki oranın mod değeri 1'dir (yani her bir türün \%50'si), ancak bu oran bir kişiden diğerine oldukça değişkendir. $\mathrm{Bu}$ nedenle, heterozigot dişilerin fenotipi, normal G6PD'den 
hemizigot bir erkeğinki kadar eksik olan G6PD'ye

kadar değişir. Şaşırtıcı bir şekilde, G6PD eksikliğinin genellikle ders kitaplarında bile 'X'e bağlı resesif' olarak nitelendirilmesi yanlış bir ifadedir. Çünkü G6PD eksikliği, sıklıkla hem biyokimyasal hem de klinik olarak heterozigotlarda ifade edilir(13).

\section{Bakla (Fabaceae)}

Doğu kökenli bir bitki olan Fabaceae, Güney Amerika'da yaygın olarak tüketilmektedir ve ilginç bir şekilde her iklim koşulunda yetişme özelliğine sahiptir. Hindistan'da yaygın olarak yetiştirilmektedir (14).

Fabaceae meyvesinin içerdiği besin öğeleri incelendiğinde, proteinler, karbonhidratlar, suda çözünen vitaminler (folik asit, niasin ve C vitamini), diyet lifi açısından zengin olduğunu ortaya konulmuştur. Büyük ölçüde, V. faba'nın tohumlu kısmı karbonhidratlardan (\%51-68), ardından proteinlerden (\%20-41) zengindir. İçeriğindeki protein fraksiyonları, globulinler (\%79), albüminler $(\% 7)$ ve glutelinlerden $(\% 7)$ oluşmaktadır (15).
V. faba tohumları beslenme için önemli olan lipidleri (doymuş, doymamış) bol miktarda içermektedir. İçeriğindeki doymuş yağ aitleripamitik asit ve stearik asit iken doymamış yağ asitleri isemiristik, pantotenik, araşidik, behenik asitler ile oleik, linoleik ve alfa linolenik asittir.

V. faba, kalsiyum $(\mathrm{Ca})$, fosfor $(\mathrm{P})$, potasyum $(\mathrm{K})$, magnezyum $(\mathrm{Mg})$, sodyum $(\mathrm{Na})$, kükürt $(\mathrm{S})$, alüminyum (Al), bor $(\mathrm{B})$, baryum $(\mathrm{Ba})$, kobalt (Co), krom $(\mathrm{Cr})$, bakır $(\mathrm{Cu})$, demir $(\mathrm{Fe})$, galyum (Ga), lityum (Li), mangan (Mn), nikel (Ni), kurşun $(\mathrm{Pb})$, stronsiyum $(\mathrm{Sr})$, sçinko $(\mathrm{Zn})$ minerallerini içermektedir. Tüm bu veriler baklanın besin değerinin yüksek olduğunu göstermektedir (16).

Yüksek besin değerine rağmen V. faba, ayrıca visin ve konvisin gibi pek çok anti-besinsel bileşen içerir ve bu iki bileşik favizm adı verilen ölümcül hastalığa neden olabilir (17).

\section{Favizm}

Favizm, bakla tüketiminden kaynaklanan hemolitik anemiyi tanımlamak için kullanılan bir terimdir. G6PD eksikliği ile ilişkisi bilimsel ve tıbbi literatürde yer almıştır. $\mathrm{Bu}$ nedenle, bakla G6PD 
eksikliği olan hastalarda kaçınılması gereken bir besin olarak onaylanmıştır (18).

Antik çağlardan beri bilinen, G6PD eksikliği olan hastalarda bakla alımının neden olduğu akut hemoliz, oksidatif ilaçların neden olduğu hemoliz ile güçlü benzerlikler taşımaktadır.

Bakladan izole edilen iki pirimidin glikozit (visin ve konvisin), favizmi indükleyen faktörler olarak gösterilmiştir. $\mathrm{Bu}$ pirimidinlerin içindeki aktif maddeler, aglikon türevleridir. Divisin, visinin anglikon türevidir.

$\mathrm{Bu}$ oksitleyici maddelerin her ikisi de G6PD eksikliği olan hücrelerin zaten azalmış olan glutatyon üretme kapasitesini hızla azaltmaktadır. Ayrıca, kırmızı kan hücresi işlevi üzerinde de doğrudan etkileri vardır (19).

In vitro çalışmalar, divisinin, glutatyon gibi hidrojen peroksit uzaklaştırılmasına katkıda bulunan ve normal aktivitenin korunması için NADPH gerektiren bir enzim olan katalaz aktivitesini azalttığını göstermiştir.

Benzer şekilde, eritrositlerin in vitro izouramil tedavisi, G6PD eksikliği olan bireylerde eritrosit sekestrasyonunda bir faktör olduğu varsayılan hücresel membran deformabilitesinde belirgin bir azalmaya neden olmuştur.

Akut intravasküler hemoliz (yani, kan dolaşımındaki eritrositlerin zar bütünlüğünün kaybı) favizmin en yaygın şeklidir (20).

Favizm geliştiren bireylerde G6PD enzimi neredeyse her zaman eksiktir, ancak polimorfizm nedeniyle, eksikliği olan tüm kişiler baklaya duyarlı değildir. Bu nedenle anemi, genellikle en şiddetli ve en yaygın olarak sınıf I varyantında görülmektedir. Akdeniz varyantında (sınıf II) biraz daha azdır. G6PD A varyantı (sınıf III) olan hastalarda zaman zaman favizm gözlenmiştir. Favizm, genellikle çocuklarda (1-5 yaş arası) daha sı1k görülür, ancak yetişkinlerde de ortaya çıkabilmektedir (21).

Bakladaki visin ve konvisin içeriği çeşide, yetiştirme koşullarına ve tohumların hasat edildiği aşamaya göre değişmektedir. Taze bakla tohumları, bitkilerin en yüksek oranda yenen kısımlarıdır. $\mathrm{Bu}$ pirimidin glikozitlerin kuru bakladaki miktarı, taze bakladakinden yaklaşık \%50 daha düşüktür. Ek olarak, taze tohumlar semptomların şiddetinde rol oynayabilecek beta-glukozidazlar ve askorbat içermektedir. 
Akdeniz Havzası'ndaki favizmin mevsimsel en yüksek insidansı, fasulyenin hasadı ile örtüşmektedir. $\mathrm{Bu}$ nedenle, çiğ ve taze baklanın favizme neden olma olasılığ daha yüksek olarak kabul edilmektedir. Sıcaklığın bakla üzerindeki etkilerinin veya tüketilmeden önce baklaların uzun süreli depolanmasının sonuçlarının değerlendirilmesini sağlayacak çok az veri bulunmaktadır.

Beta-glukozidaz enzimi ve askorbatın pişirmeye karşı duyarlı oldukları, visin ve konvisinin ise pişirmeye ve çimlendirme işlemlerine nispeten dirençli olarak kabul edilmektedir (22).

Favizm, genellikle bakla yendikten yaklaşık 24 saat sonra akut hemolitik anemi olarak ortaya çıkmaktadır. Hemoglobinüri, bilirubin konsantrasyonları daha düşük olmasına rağmen, ilaçlar veya enfeksiyon tarafindan tetiklenen hemolitik krizlerden kaynaklanandan daha şiddetlidir.

Anemi genellikle akut ve şiddetli olup, bazı hastalarda iskemi veya hemoglobin dökümlerinin çökelmesi nedeniyle akut böbrek yetmezliğine yol açmaktadır. Favizm hastalarında meydana gelen oksidatif hasar, eritrositlerde bir dizi değişikliğe neden olarak bu hücrelerin dolaşımdan hızlı bir şekilde temizlenmesine neden olmaktadır. $\mathrm{Bu}$ nedenle, favizmli hastalarda hemolitik olaylar intravasküler veya ekstravasküler olabilmektedir. Şiddetli hemolitik atak geçiren bir hasta, kan nakli gerektirebilmektedir. G6PD eksikliği prevalansının yüksek olduğu bölgelerde, neonatal tarama ve sağlık eğitimi yoluyla yapılan önleme kampanyaları favizm insidansını büyük ölçüde azaltmıştır (23).

\section{Nutrigenetik}

Nutrigenetiğin kökleri klasik genetik içindedir. Nutrigenetik, hastalık etiyolojisinde rol oynayabilecek beslenme ve genetik faktörlerin etkileşimi ile ilgilidir. Temel amacı, özellikle tek nükleotid polimorfizmi (SNP) olarak bilinen genetik varyasyonun, bireyin diyet alımına verdiği yanıt üzerindeki etkisini, özellikle genetik varyasyonun bireyin metabolik durumunu nas1l etkilediğini araştırmaktır. Yani belirli diyetlerin veya diyet bileşenlerinin bireye riskleri ve yararları ile ilgili öneriler oluşturmaktır. Aynı zamanda "kişiye özel beslenme" ve "bireyselleştirilmiş beslenme" olarak da adlandırılmıştır. Örneğin, bir bireyin kafeine yanıt1, CYP1A2 genindeki genetik 
polimorfizm nedeniyle değişir. Bu gen, karaciğerde sentezlenen ve kafeini demetile eden bir enzimi kodlar ve genin bazı varyantları kafeini diğerlerinden daha hızlı bir şekilde demetile etmektedir. Özetle, nutrigenetik, bir bireyin genotipik kompozisyonunun diyet alımına fenotipik yanıtı nasıl etkilediği ile ilgilenir (24).

Nutrigenetik kavramının kökenleri tam olarak bilinmemektedir, ancak tarihsel olarak, ünlü Yunan aforizması "Biri için yemek, diğerleri için acı zehirdir." (Lucretius), bireyler arası ilk yazılı referanslardan biridir. Modern zamanlarda, genler ve diyet arasındaki etkileşimi açıklayan ilk raporlardan biri 1945 yılında yazılmıştır.

Nutrigenetik terimi çok daha sonra ortaya çıkmış ve ilk olarak Brennan ve Mulligan'ın 1975 tarihli bir kitabının başlığında görülmüştür. Bununla birlikte, belirli genleri araştırmak ve diyet faktörlerine yanıt olarak değişkenlikle ilişkili varyantları belirlemek için teknik kapasiteye 1980'lere kadar ulaşılamamıştır (25).

Metilen-tetra-hidro folat redüktaz geni (MTHFR), bir gen-besin etkileşimi sunan iyi bilinen bir nutrigenetik örneğidir. Spesifik olarak, bu enzim 5, 10 metilente-trahidrofolatın 5 metiltetrahidrofolat adı verilen bir moleküle dönüştürülmesi için gereklidir. Bu reaksiyon, amino asit homosisteinini başka bir amino aside, metionine dönüştüren çok aşamalı işlem için gereklidir. MTHFR, folik asit metabolizmasinda ve normal kan homosistein seviyesinin korunmasında rol oynamaktadır. Belirli bir MTHFR geni SNP'si (C677T ve A1298C), özellikle diyette folik asit eksikliği varsa, taşıyıcıların kanındaki yüksek homosistein seviyeleri ile ilişkilidir. Düşük MTHFR enzim aktivitesine sahip bireylerde, inflamasyon ve kalp hastalığı, doğum kusurları, zor gebelikler ve potansiyel olarak detoksifikasyon yeteneğinde bozulma ile ilişkilendirilen yüksek homosistein seviyeleri görülebilmektedir. Folat, B6 ve B12'deki besin eksiklikleri, yüksek homosistein ile ilişkilendirilmiştir (26).

Galaktoz-1-fosfat üridiltransferaz (GALT) geni ile fenilalanin hidroksilaz ve Glukoz-6 fosfat dehidrojenize (G6PD) genindeki farklı mutasyonlar sırasıyla Galaktozemi, Fenilketonüri (PKU) ve Favizm hastalıklarına neden olmuştur. Enzim polimorfizmlerinin diğer örnekleri, SNP'lerin gen ekspresyonunu nasıl değiştirdiğini 
gösteren Laktaz-florizin hidrolaz gen (LPH)

polimorfizmlerini içermektedir. Bu polimorfizm, hipolaktazi ile ilişkili laktaz-florizin hidrolaz geninin (LPH) yukarı regülasyonu diyet laktoza tolerans1 değiştirmektedir ve LPH41'in farklı ekspresyonuna izin vermektedir (27).

\section{SONUÇ}

Dünya çapında en az 400 milyon insan G6PD eksikliği genini taşımaktadır. Ancak, bunların çoğunluğu yaşamları boyunca klinik olarak asemptomatik kalmaktadır. Bununla birlikte, G6PD eksikliği olan bireylerin bir kısmının, tedavi süreci yetersiz yönetilirse ölüme veya kalıcı nörolojik hasara neden olabilen neonatal sarılık veya akut hemolitik anemi geliştirmesi olasıdır. Ayrıca, G6PD eksikliği olan hastalar bakla yemekten kaçınmalı ve akut hemoliz ataklarının riskleri ve bu atakların nasıl tanınacağ bilgilendirilmelidirler.

Yeni genetik biliminin, hem kronik hastalıkları önlemede hem de yönetmede beslenme araştırmaları için muazzam etkileri vardır. Gelişen genetik ve teknolojik devrimle birlikte, araştırmalara devam eden yatırımlar, hastalık süreçlerini anlamak, sağlığa yönelik riskleri önlemek ve dünya çapında yaşam kalitesini iyileştirmek amacıyla yeni yaklaşımlar geliştirmek için benzeri görülmemiş firsatlar sunmaktadır.

Böylece nutrigenetik, bireyin genetik profiline dayalı olarak bireysel beslenme ihtiyaçlarının değerlendirilmesine ve ayrıca kronik hastalıkların iyileştirilmesine ve önlenmesine yardımcı olacaktır. Bu nedenle, herkesin genetik devrimden faydalanabilmesi, diyet ve sağlık arasındaki ilişkiyi anlamak için bu alanda daha fazla araştırmaya ihtiyaç vardır.

\section{KAYNAKLAR}

1. Luzzatto L, Arese P. Favism and glucose-6-phosphate dehydrogenase deficiency. New England Journal of Medicine. 2018; 378(1): 60-71.

2. Nkhoma ET, Poole C, Vannappagari V, Hall SA, \& Beutler E. The global prevalence of glucose-6-phosphate dehydrogenase deficiency: a systematic review and meta-analysis. Blood Cells, Molecules, and Diseases. 2009;42(3): 267-278.

3. Wajcman H, Galactéros F. Glucose 6-phosphate dehydrogenase deficiency: a protection against malaria and a risk for hemolytic accidents. Comptes Rendus Biologies, 2004; 327(8): 711-720.

4. Gómez-Manzo S, Marcial-Quino J, Vanoye-Carlo A, et al. Glucose-6-phosphate dehydrogenase: update and analysis of new mutations around the world. International Journal of Molecular Sciences. 2016;17(12): 2069.

5. Carson PE, Flanagan CL, Ickes CE, \& Alving AS. Enzymatic deficiency in primaquine-sensitive erythrocytes. Science. 1956; 124(3220): 484-485.

6. Ravikumar N, Greenfield G. Glucose-6-phosphate Dehydrogenase Deficiency: A Review. International Journal of Medical Students. 2020;8(3): 281-287.

7. Mehta AB. Glucose-6-phosphate dehydrogenase deficiency. Postgraduate Medical Journal. 1994; 70(830): 871-877.

8. Deng Z, Yang F, Bai Y, et al. Co-inheritance of glucose-6phosphate dehydrogenase deficiency mutations and hemoglobin $\mathrm{E}$ in a Kachin population in a malaria-endemic region of Southeast Asia. PloS One. 2017;12(5): e0177917.

9. Gómez-Manzo S, Marcial-Quino J, Vanoye-Carlo A, et al. Glucose-6-phosphate dehydrogenase: update and analysis of 
new mutations around the world. International Journal of Molecular Sciences. 2016; 17(12): 2069.

10. Beutler E. Glucose-6-phosphate dehydrogenase deficiency: a historical perspective. Blood. 2008; 111(1): 16-24.

11. Frank JE. Diagnosis and management of G6PD deficiency. American Family Physician. 2005;72(7):1277-1282.

12. Cappellini MD, Sampietro M, Toniolo D, et al. (1994). G6PD Ferrara I has the same two mutations as G6PD A (-) but a distinct biochemical phenotype. Human Genetics, 1994; 93(2): $139-142$.

13. Luzzatto L, Ally M, Notaro R. Glucose-6-phosphate dehydrogenase deficiency. Blood, The Journal of the American Society of Hematology. 2020; 136(11): 1225-1240.

14. Iriti M, Varoni EM. Pulses, healthy, and sustainable food sources for feeding the planet. International Journal of Molecular Sciences. 2017; 18(2): 255-256.

15. Vioque J, Alaiz M, Girón-Calle J. Nutritional and functional properties of Vicia faba protein isolates and related fractions. Food Chemistry.2012; 132(1): 67-72.

16. Prabhu SD, Rajeswari DV. Nutritional and Biological properties of Vicia faba L.: A perspective review. International Food Research Journal. 2018; 25(4): 1332-1340.

17. Coda R, Melama L, Rizzello CG, et al. Effect of air classification and fermentation by Lactobacillus plantarum VTT E-133328 on faba bean (Vicia faba L.) flour nutritional properties. International Journal of Food Microbiology. 2015; 193: 34-42.

18. Song M. Preventing favism by selecting faba bean mutants using molecular markers. STEM Fellowship Journal.2017; 3(1): 2-6.

19. Arese P, Gallo V, Pantaleo A, Turrini F. Life and death of glucose-6-phosphate dehydrogenase (G6PD) deficient erythrocytes-role of redox stress and band 3 modifications. Transfusion Medicine and Hemotherapy. 2012; 39(5): 328334.

20. Getachew F, Vandenberg A, Smits J. A practical toxicity bioassay for vicine and convicine levels in faba bean (Vicia faba). Journal of the Science of Food and Agriculture. 2018; 98(13): 5105-5111.

21. Ahmed SN. Do favic patients resume fava beans ingestion later in their life, a study for this, and a new hypothesis for favism etiology. Hematology/Oncology and Stem Cell Therapy.2013; 6(1): 9-13.

22. Al-Mendalawi MD. A hemolysis trigger in glucose-6phosphate dehydrogenase enzyme deficiency. Vicia sativa (vetch). Saudi Medical Journal. 2009;30(7): 974-975.

23. Cappellini MD, Fiorelli G. Glucose-6-phosphate dehydrogenase deficiency. The Lancet. 2008; 371(9606): 6474.

24. Marcum JA. Nutrigenetics/nutrigenomics, personalized nutrition, and precision healthcare. Current Nutrition Reports. 2020; 9(4): 338-345.

25. Bouchard C, Ordovas JM. Fundamentals of Nutrigenetics and Nutrigenomics. Progress in Molecular Biology and Translational Science.2012; 108:1-15.

26. Sharma P, Dwivedi S. Nutrigenomics and nutrigenetics: New insight in disease prevention and cure. Indian Journal of Clinical Biochemistry.2017; 32(4): 371-373.

27. Barak S, Mudgil D, Khatkar BS. Nutrigenomics: the emerging face of nutrition. International Journal of Current Research and Review. 2011; 3(6):105-115. 